\title{
molecules
}

ISSN 1420-3049

(C) 2008 by MDPI

www.mdpi.org/molecules

Full Paper

\section{Antiplatelet Aggregation Coumarins from the Leaves of Murraya omphalocarpa}

Yi-Chen Chia ${ }^{1}$, Fang-Rong Chang ${ }^{2}$, Jinn-Chyi Wang ${ }^{1}$, Chin-Chung Wu ${ }^{2}$, Michael Y.-N. Chiang ${ }^{3}$, Yu-Hsuan Lan ${ }^{2}$, Keh-Shaw Chen ${ }^{1, *}$ and Yang-Chang $\mathrm{Wu}^{2, *}$

${ }^{1}$ Department of Food Science and Technology, Ta-Jen University, Ping Tung Hsien, Taiwan E-mail: ycchia@mail.tajen.edu.tw, jicy.wang@msa.hinet.net, kschen@mail.tajen.edu.tw

${ }^{2}$ Graduate Institute of Natural Products, Kaohsiung Medical University, Kaohsiung 807, Taiwan E-mail: aaronfrc@kmu.edu.tw, ccwu@kmu.edu.tw, lanyh@mail.cmu.edu.tw,yachwu@kmu.edu.tw

${ }^{3}$ Department of Chemistry, National Sun Yat-Sen University, Kaohsiung 807, Taiwan E-mail: michael@mail.nsysu.edu.tw

* Authors to whom correspondence should be addressed; Yang-Chang Wu, E-mail: yachwu@kmu.edu.tw; Tel: (+886)-7-3121101 ext 2197; Fax: (+886)-7-3114773; or Keh-Shaw Chen, E-mail: kschen@mail.tajen.edu.tw; Tel: (+886)-8-7624002 ext 359; Fax: (+886)-8-7621902

Received: 20 November 2007; in revised form: 7 January 2008 / Accepted: 7 January 2008 / Published: 21 January 2008

Abstract: Using a bioactivity-guided fractionation method, two coumarins: minumicroline acetonide (1) and epimurpaniculol senecioate (2), were isolated from the leaves of Murraya omphalocarpa Hayata (Rutaceae). Compound 1 had been previously synthesized and was now isolated from natural sources for the first time, and compound 2, possessing a negative optical rotation value, is new. The structures and their stereochemistry were fully elucidated on the basis of spectroscopic and X-ray crystallographic techniques. Both compounds $\mathbf{1}$ and $\mathbf{2}$ are active in the antiplatelet aggregation assay. Interestingly, the possible acetonide artifact $\mathbf{1}$ displayed significant antiplatelet aggregation induced not only by AA and collagen but also by platelet activating factor (PAF).

Keywords: Murraya omphalocarpa, coumarin, epimurpaniculol senecioate, X-ray, antiplatelet. 


\section{Introduction}

Murraya omphalocarpa Hayata (Rutaceae) is a shrub or small tree that grows wild at low altitudes in Taiwan [1]. It has been rarely studied and no traditional medicinal use has been reported before. Nine coumarins, two flavones, and phytosterols have been isolated from the fruits and leaves in previous phytochemical studies [2-4]. Of these, three compounds were reported to exhibit significant antiplatelet aggregation induced by arachidonic acid (AA) and collagen [4]. In the continuing phytochemical investigation, two coumarins, minumicroline acetonide (1) [5-6] and epimurpaniculol senecioate (2), were isolated from the methanoic extracts of the leaves of this plant by the way of bioactivity-guided fractionation method. Compound 2, with a negative optical rotation value, is a new compound, which is different in comparison with the previous data [7]. Compounds 1 and 2 are active in antiplatelet aggregation activity induced by AA and collagen. Furthermore, the possible acetonide artifact 1 displayed significant antiplatelet aggregation induced by platelet activating factor (PAF).

Figure 1. Structures of compounds 1 and 2.

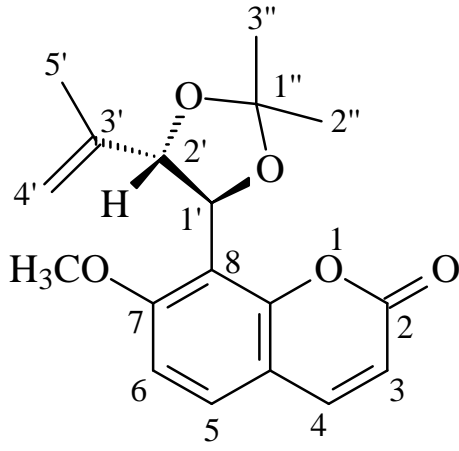

1

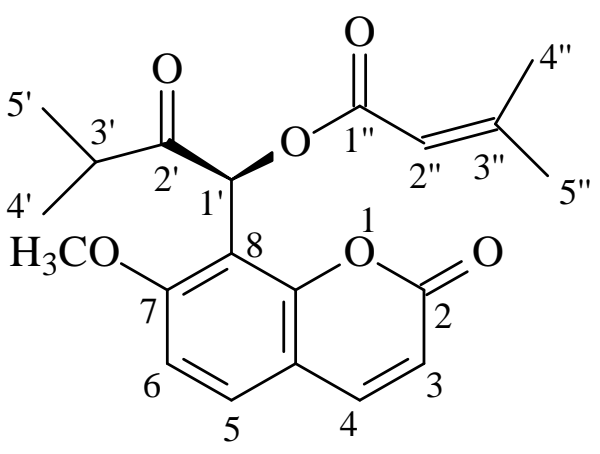

2

\section{Results and Discussion}

Compound 1 was isolated as colorless prisms and analyzed as $\mathrm{C}_{18} \mathrm{H}_{20} \mathrm{O}_{5}$ (calcd. 316.1311) from the molecular ion observed at $\mathrm{m} / \mathrm{z} 316.1311$ in its HR-EI-MS. Its ${ }^{1} \mathrm{H}-\mathrm{NMR}$ displayed signals of two pairs of AB-type doublets [ $\delta 6.24$ and 7.60 (each $1 \mathrm{H}, J=9.6 \mathrm{~Hz}, \mathrm{H}-3$ and H-4), and $\delta 7.41$ and 6.87 (each $1 \mathrm{H}, J=8.8 \mathrm{~Hz}, \mathrm{H}-5$ and $\mathrm{H}-6)]$ as well as a methoxyl singlet at $\delta 3.92$. This, together with its UV and IR data, suggested the presence of a 7-methoxy-8-substituted coumarin nucleus [5-6]. The two spincoupled doublets at $\delta 5.56(\mathrm{~J}=8.8 \mathrm{~Hz})$ and $5.01(\mathrm{~J}=8.8 \mathrm{~Hz})$ revealed the presence of two vicinal protons attached to benzylic or allylic oxygenated carbons. The terminal vinylic and allylic methyl groups were determined by ${ }^{1} \mathrm{H}-\mathrm{NMR}$ signals at $\delta 4.95,4.84$, and 1.53 , in addition to ${ }^{13} \mathrm{C}-\mathrm{NMR}$ signals at $\delta$ 113.5, 141.5, and 17.6. Two three-proton singlets at $\delta 1.73$ and 1.69, and ${ }^{13} \mathrm{C}-\mathrm{NMR}$ signals at $\delta 109.6$, 27.3, and 27.0 indicated the presence of an acetonide moiety, which is attached to C-1' and C-2'. Based on chemical evidence, spectral data and previous literature reports [5-6], the structure of compound $\mathbf{1}$ was thus established. The physical data is described in detail in the Experimental. According to the literature [5], compound $\mathbf{1}$ had been previously synthesized and the absolute configuration was confirmed its CD spectrum. In addition, an X-ray diffraction analysis of a single crystal was 
undertaken. The X-ray structure (Figure 2) confirmed that the absolute configuration of 1 is $1^{\prime} R, 2^{\prime} R$. Compound $\mathbf{1}$ was thus isolated from natural sources for the first time and may be an extraction artifact.

Figure 2. X-ray diffraction analysis of compounds 1 and 2.

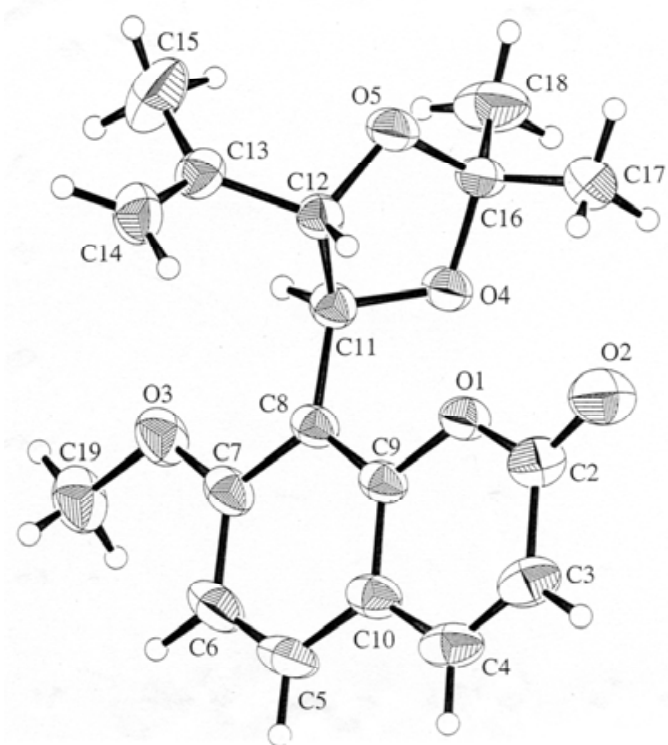

1

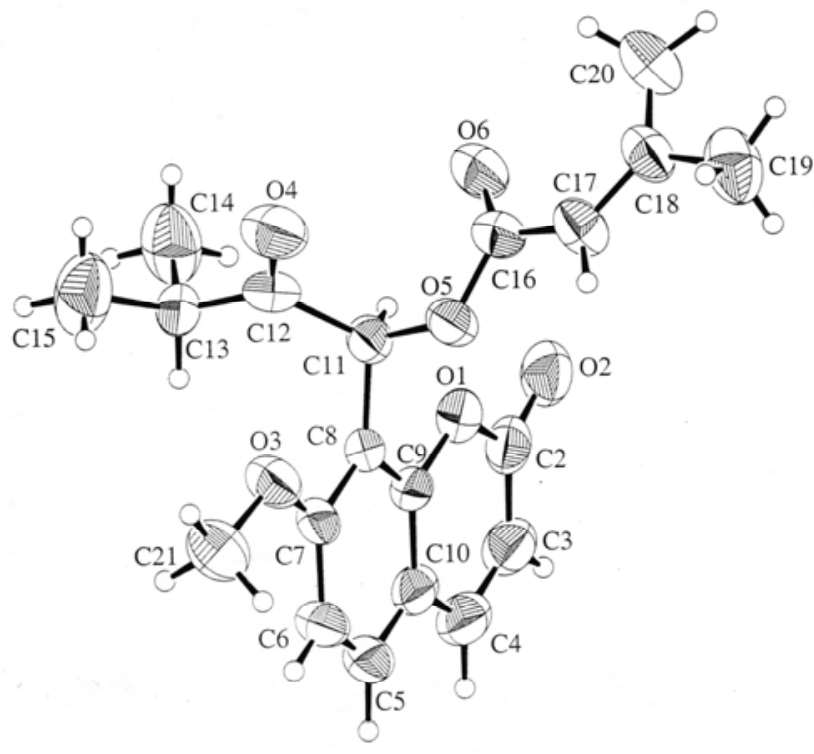

2

Compound 2 was isolated as colorless prisms and analyzed for $\mathrm{C}_{20} \mathrm{H}_{22} \mathrm{O}_{6}$ according to the molecular ion at $\mathrm{m} / \mathrm{z} 358.1420$ (calcd. 358.1424) in its HR-EI-MS. UV, IR, and ${ }^{1} \mathrm{H}-\mathrm{NMR}$, which displayed signals of two pairs of AB-type doublets and a methoxyl singlet, suggested the presence of a 7 -methoxy-8-substituted coumarin nucleus as in $\mathbf{1}$. The unusual singlet at $\delta 7.02$ revealed the presence of a $\beta$-oxo benzylic esterified methine. A $2^{\prime}$-methyl-1'-propanone residue was established by the ${ }^{1} \mathrm{H}$ NMR data [ $\delta 1.03$ and 1.19 (each $3 \mathrm{H}, \mathrm{d}, J=7.2 \mathrm{~Hz}$ ) and $\delta 2.95\left(1 \mathrm{H}\right.$, hept., $J=7.2 \mathrm{~Hz}$ )], ${ }^{13} \mathrm{C}-\mathrm{NMR}$ data ( $\delta$ 209.1, 36.2, 18.8 and 18.1), and a mass fragment ion at $\mathrm{m} / \mathrm{z} 287$ [M-COCH$\left.(\mathrm{Me})_{2}\right]^{+}$. Two doublet signals at $\delta 1.88$ and 2.18 (each $3 \mathrm{H}, \mathrm{d}, J=1.2 \mathrm{~Hz}$, allylic coupling) and a singlet proton at $\delta 5.79,{ }^{13} \mathrm{C}$ NMR signals at $\delta 165.0,158.5,115.4,27.4$, and 20.4, in addition to a mass fragment ion at $\mathrm{m} / \mathrm{z} 275$ $\left[\mathrm{M}-\mathrm{COCH}=\mathrm{C}(\mathrm{Me})_{2}\right]^{+}$, indicated the presence of a 3"-methyl-1"-oxo-2"-butenyl residue attached at C$1^{\prime}$ through an oxy-linkage. The above observation and the analysis of 2D NMR spectra led to the establishment of the structure as 2 . Except for the optical rotation value of 2 , $[\alpha]_{\mathrm{D}}^{24}=-40.1$, the spectral data were almost identical with those of murpaniculol senecioate with $[\alpha]_{\mathrm{D}}^{24}=+123.3$ [7]. In order to confirm the stereochemistry of $\mathbf{2}$, an X-ray diffraction analysis of a single crystal was taken. The X-ray structure (Figure 2) indicated that the relative configuration of 2 is $1^{\prime} S^{*}$. Thus, the structure of 2 was fully elucidated as a new enantiomer of murpaniculol senecioate, which we have named epimurpaniculol senecioate.

\section{Biological activity}

The antiplatelet effects of these two compounds were studied on the aggregation of washed rabbit platelets induced by thrombin (Thr) $(0.1 \mathrm{U} / \mathrm{mL})$, arachidonic acid (AA) (100 $\mu \mathrm{M})$, collagen (10 $\mu \mathrm{g} / \mathrm{mL}$ ), and platelet activating factor (PAF) (1 ng/mL). As shown in Table 1 , compound 1 showed 
significant inhibition of AA- and collagen- induced platelet aggregation, and strong inhibition induced by PAF, which was different from other coumarins isolated from this species [4]. Compound 2 also displayed significant inhibitory activity on collagen- and AA- induced platelet aggregation. The bioactive results indicated its chemoprotective potential in cardiovascular diseases.

Table 1. Effects of compounds $\mathbf{1}$ and $\mathbf{2}$ on the platelet aggregation induced by Thr, AA, collagen, and PAF in washed rabbit platelets.

\begin{tabular}{ccccc}
\hline \multirow{2}{*}{ Compound } & \multicolumn{4}{c}{ Aggregation (\%) } \\
\cline { 2 - 5 } & Thr (0.1 U/mL) & AA (100 $\boldsymbol{\mu M})$ & Col. (10 $\mathbf{~ g g / m L )}$ & PAF (1 ng/mL) \\
\hline $\mathbf{1}(100 \mu \mathrm{g} / \mathrm{mL})$ & $85.0 \pm 1.2^{*}$ & $0.0 \pm 0.0^{* * *}$ & $0 \pm 0^{* * *}$ & $24.7 \pm 3.8^{* * *}$ \\
$(50 \mu \mathrm{g} / \mathrm{mL})$ & & $73.7 \pm 3.3$ & $27.0 \pm 11.5^{* * *}$ & $60.7 \pm 1.5^{* * *}$ \\
$(20 \mu \mathrm{g} / \mathrm{mL})$ & & & $70.0 \pm 1.9^{* *}$ & \\
$\mathbf{2}(100 \mu \mathrm{g} / \mathrm{mL})$ & $74.3 \pm 0.5^{* *}$ & $53.0 \pm 2.2^{* * *}$ & $0 \pm 0^{* * *}$ & $70.0 \pm 1.2^{* * *}$ \\
$(50 \mu \mathrm{g} / \mathrm{mL})$ & & $70.3 \pm 4.0^{* *}$ & $0 \pm 0^{* * *}$ & \\
$(20 \mu \mathrm{g} / \mathrm{mL})$ & & & $63.7 \pm 5.5^{*}$ & \\
Control & $80.0 \pm 1.6$ & $83.3 \pm 0.5$ & $81.3 \pm 3.8$ & $84.0 \pm 1.7$ \\
\hline
\end{tabular}

Platelets were preincubated with DMSO (0.5\%, control), or tested compounds at $37^{\circ} \mathrm{C}$ for 3 min, then Thr $(0.1 \mathrm{U} / \mathrm{mL})$, AA $(100 \mu \mathrm{M})$, collagen $(10 \mu \mathrm{g} / \mathrm{mL})$ or PAF $(1 \mathrm{ng} / \mathrm{mL})$ was added.

Percentages of aggregation are presented as means \pm S. E. $(n=3 \sim 4)$.

${ }^{*} \mathrm{p}<0.05, * * \mathrm{p}<0.01, * * * \mathrm{p}<0.001$ as compared with the respective control.

\section{Experimental}

\section{General}

Melting points were determined using a Yanagimoto micro-melting point apparatus and are uncorrected. Optical rotations were measured with a JASCO P-1020 digital polarimeter. The UV spectra were obtained on a Hitachi 200-20 spectrophotometer, and IR spectra were measured on a Hitachi 260-30 spectrophotometer. ${ }^{1} \mathrm{H}-\mathrm{NMR}$ (400 MHz) and ${ }^{13} \mathrm{C}-\mathrm{NMR}$ (100 MHz) spectra were recorded with a Varian Unity-Plus NMR spectrometer in $\mathrm{CDCl}_{3}$ using TMS as an internal standard. EI-MS were collected on a JEOL JMS-SX/SX 102A mass spectrometer having a direct inlet system. HR-EI-MS were measured on a JEOL JMS-HX 110 mass spectrometer. Si gel 60 (Merck, 230-400 mesh) was used for column chromatography. Pre-coated Si gel plates (Merck, Kieselgel 60 F-254, 0.20 $\mathrm{mm}$ ) were used for analytical TLC, and precoated Si gel plates (Merck, Kieselgel 60 F-254, $0.50 \mathrm{~mm}$ ) were used for preparative TLC. Spots were detected by spraying with $30 \% \mathrm{H}_{2} \mathrm{SO}_{4}$ and then heating on a hot plate.

\section{Plant Material}

Fresh leaves of $M$. omphalocarpa were collected from Pingtung County, Taiwan, in September 1999, and identified by Dr. Hsin-Fu Yen (Associate Researcher of Plants Taxonomy, National Museum of Natural Science, Taichung, Taiwan). A voucher specimen (Rutaceae murraya 1) was 
deposited in the Graduate Institute of Natural Products, Kaohsiung Medical University, Kaohsiung, Taiwan, Republic of China.

\section{Extraction and Isolation}

The fresh leaves $(1.53 \mathrm{~kg})$ of $M$. omphalocarpa were extracted five times with $\mathrm{MeOH}(5 \mathrm{~L})$ at room temperature. The combined $\mathrm{MeOH}$ extracts were evaporated and partitioned, as guided by in vitro antiplatelet aggregation tests, to yield $\mathrm{CHCl}_{3}$ - and $\mathrm{H}_{2} \mathrm{O}$-soluble extracts. A portion of the $\mathrm{CHCl}_{3}$ soluble extract (20.3 g) was chromatographied over silica gel (1000 g) and eluted with $n$ hexane/ $\mathrm{CHCl}_{3} / \mathrm{MeOH}$ mixtures (100:0:0, 50:1:0, 10:1:0, 5:1:0, 1:1:0, 1:2:0, 0:100:0, 0:50:1, 0:25:1, $0: 10: 1,0: 8: 1,0: 6: 1$, and $0: 4: 1$ ) of increasing polarity to yield 100 fractions (120 mL each). The fractions were combined into 16 fractions (C1 C16) based on TLC. Fr. C6 ( $n$-hexane/ $\mathrm{CHCl}_{3}$ 5:1, 1.63 g) were further purified by silica gel column chromatography (145 g) using the same solvent system to give compounds 1 (25 mg) and 2 (21 mg).

Minumicroline acetonide (1): colorless prisms $\left(\mathrm{CHCl}_{3}\right)$; mp $135-137^{\circ} \mathrm{C} ;[\alpha]_{\mathrm{D}}^{24}+85.2^{\circ}\left(c 0.12, \mathrm{CHCl}_{3}\right)$; UV (MeOH) $\lambda_{\max } \mathrm{nm}(\log \varepsilon): 240$ (3.56), 260 (4.06), 320 (4.25); IR $\mathrm{v}_{\max }(\mathrm{KBr}) \mathrm{cm}^{-1}: 1750,1650 ;{ }^{1} \mathrm{H}-$ NMR $\delta: 7.60(1 \mathrm{H}, \mathrm{d}, J=9.6 \mathrm{~Hz}, \mathrm{H}-4), 7.41(1 \mathrm{H}, \mathrm{d}, J=8.8 \mathrm{~Hz}, \mathrm{H}-5), 6.87(1 \mathrm{H}, \mathrm{d}, J=8.8 \mathrm{~Hz}, \mathrm{H}-6)$, $6.24(1 \mathrm{H}, \mathrm{d}, J=9.6 \mathrm{~Hz}, \mathrm{H}-3), 5.56\left(1 \mathrm{H}, \mathrm{d}, J=8.8 \mathrm{~Hz}, \mathrm{H}-1^{\prime}\right), 5.01\left(1 \mathrm{H}, \mathrm{d}, J=8.8 \mathrm{~Hz}, \mathrm{H}-2^{\prime}\right), 4.95(1 \mathrm{H}$, d, $\left.J=2.2 \mathrm{~Hz}, \mathrm{H}-4^{\prime}\right), 4.84\left(1 \mathrm{H}, \mathrm{d}, J=2.2 \mathrm{~Hz}, \mathrm{H}-4^{\prime}\right), 3.92\left(3 \mathrm{H}, \mathrm{s}, \mathrm{OCH}_{3}\right), 1.73\left(3 \mathrm{H}, \mathrm{s}, \mathrm{H}-2^{\prime \prime}\right), 1.69$ (3H, s, H-3"), 1.53 (3H, s, H-5'); ${ }^{13}$ C-NMR $\delta: 161.4$ (s, C-2), 160.4 (s, C-7), 154.1 (s, C-8a), 143.5 (d, C-4), 141.5 (s, C-3'), 129.3 (d, C-5), 113.5 (t, C-4'), 113.4 (d, C-3), 113.1 (s, C-4a), 111.9 (s, C-8), 109.6 (s, C-1"), 108.0 (d, C-6), 81.5 (d, C-2'), 72.6 (d, C-1'), 56.2 (q, OCH OC, $_{2} 7.3$ (q, C-2"), 27.0 (q, C-3"), 17.6 (q, C-5'); HR-EI-MS m/z: 316.1311 (calcd. for $\mathrm{C}_{18} \mathrm{H}_{20} \mathrm{O}_{5}, 316.1311$ ); EI-MS m/z (\%): 316 [M] (6), 246 (100), 189 (90), 175 (30), 160 (40), 97 (95).

Epimurpaniculol senecioate (2): colorless prisms $\left(\mathrm{CHCl}_{3}\right)$; mp $111-113{ }^{\circ} \mathrm{C}$; $[\alpha]_{\mathrm{D}}^{24}-40.1^{\circ}(\mathrm{c} 0.08$, $\mathrm{CHCl}_{3}$ ); UV (MeOH) $\lambda_{\max } \mathrm{nm}(\log \varepsilon): 240$ (3.58), 260 (4.05), 325 (4.26); IR $v_{\max }(\mathrm{KBr}) \mathrm{cm}^{-1}: 1730$ 1700; ${ }^{1} \mathrm{H}-\mathrm{NMR} \delta: 7.62$ (1H, d, $\left.J=9.6 \mathrm{~Hz}, \mathrm{H}-4\right), 7.46$ (1H, d, $\left.J=8.8 \mathrm{~Hz}, \mathrm{H}-5\right), 7.02$ (1H, s, H-1'), 6.87 (1H, d, $J=8.8 \mathrm{~Hz}, \mathrm{H}-6), 6.25$ (1H, d, $J=9.6 \mathrm{~Hz}, \mathrm{H}-3), 5.79$ (1H, s, H-2"), 3.90 (3H, s, OCH $), 2.95$ (1H, hept., $J=7.2 \mathrm{~Hz}, \mathrm{H}-3^{\prime}$ ), 2.18 (3H, d, $J=1.2 \mathrm{~Hz}, \mathrm{H}-4^{\prime \prime}$ ), 1.88 (3H, d, $\left.J=1.2 \mathrm{~Hz}, \mathrm{H}-5^{\prime \prime}\right), 1.19$ (3H, d, $J=7.2 \mathrm{~Hz}, \mathrm{H}-5^{\prime}$ ), 1.03 (3H, d, $J=7.2 \mathrm{~Hz}, \mathrm{H}-4^{\prime}$ ); ${ }^{13} \mathrm{C}-\mathrm{NMR} \delta: 209.1$ (s, C-2' ), 165.0 (s, C-1'), 160.8 (s, C-2), 159.9 (s, C-7), 158.5 (s, C-3"), 153.6 (s, C-8a), 143.2 (d, C-4), 129.8 (d, C-5), 115.4 (d, C-2"'), 113.7 (d, C-3), 113.1 (s, C-4a), 113.0 (s, C-8), 107.8 (d, C-6), 68.5 (d, C-1'), 56.4 (q, OCH $), 36.2$ (d, C-3'), 27.4 (q, C-5"), 20.4 (q, C-4"), 18.8 (q, C-5') 18.1 (q, C-4'); HR-EI-MS m/z: 358.1420 (calcd. for $\left.\mathrm{C}_{20} \mathrm{H}_{22} \mathrm{O}_{6}, 358.1424\right)$; EI-MS m/z (\%): 358 [M] (3), 287 (8), 275(20), 205 (30), 83 (100).

\section{X-ray Structure Determination}

Crystals of $\mathbf{1}$ and 2 suitable for diffraction study were all obtained from $\mathrm{MeOH} / \mathrm{CHCl}_{3}$ solvent mixtures (1:1). Structures were solved via direct method (SIR92) and refined with a full-matrix leastsquares program using the TeXsan [8] software package. Anisotropic refinement was carried out for all non-hydrogen atoms. Hydrogen atoms were calculated according to their idealized positions (dC- 
$\mathrm{H}=0.95 \mathrm{~A}^{\circ}$ ). Crystal data of $\mathbf{1}$ : formula $=\mathrm{C}_{18} \mathrm{H}_{20} \mathrm{O}_{5}$; crystal dimensions $=0.20 \times 0.60 \times 0.62 \mathrm{~mm}$; lattice parameters: $\mathrm{a}=8.733$ (2) $\AA$, $\mathrm{b}=9.244$ (3) $\AA$, $\mathrm{c}=10.945$ (3) $\AA$, $\alpha=82.07(2)^{\mathrm{o}}, \beta=89.85(2)^{\circ}, \gamma=$ $72.64(2)^{\circ}, \mathrm{V}=834.5$ (4) $\AA^{3}$; space group: P̄i (\#2); Z value: 2; $\mathrm{D}_{\text {calc: }} 1.259 \mathrm{~g} / \mathrm{cm}^{3}$; F000: 336.00; $\mu(\mathrm{MoK} \alpha): 0.91 \mathrm{~cm}^{-1}$. Crystal data of 2: formula $=\mathrm{C}_{20} \mathrm{H}_{22} \mathrm{O}_{6}$; crystal dimensions $=0.42 \times 0.76 \times 0.80$ mm; lattice parameters: $\mathrm{a}=9.457$ (6) $\AA$, $\mathrm{b}=18.600$ (8) $\AA$, $\mathrm{c}=11.231$ (7) $\AA$, $\beta=100.96(4)^{\mathrm{o}}, \mathrm{V}=1940$ (2) $\AA^{3}$; space group: P2 $1 / \mathrm{n}$ (\#14); Z value: 4; $D_{\text {calc: }} 1.227 \mathrm{~g} / \mathrm{cm}^{3} ;$ F000: $760.00 ; \mu(\mathrm{MoK} \alpha): 0.90 \mathrm{~cm}^{-1}$. The absolute configurations of the two compounds were not determined due to lack of strong scattering atoms, however, the absolute configuration of $\mathbf{1}$ can be confirmed by association with the optical rotation data. Full crystallographic data are deposited at the Cambridge Crystallographic Data Center, 12 Union Road, Cambridge CB2, 1EZ, UK with deposition numbers CCDC 674767 (for 1) and CCDC 674768 (for 2), respectively.

\section{Biological Assay}

The platelet aggregation assay was carried out according to references [9-10].

\section{Acknowledgements}

This investigation was supported by a grant from the National Science Council of the Republic of China awarded to K. S. Chen and Y. C. Wu.

\section{References}

1. Editorial Committee of the Flora of Taiwan. Flora of Taiwan 2nd Ed. Taipei: Taiwan, 1993; pp. 526-527.

2. Wu, T. S.; Tien, H. J.; Arisawa, M.; Shimizu, M; Morita, N. Flavonols and coumarins from the fruit of Murraya Omphalocarpa. Phytochemistry 1980, 19, 2227-2228.

3. Wu, T. S. Omphamurin-a new coumarin from Murraya Omphalocarpa. Phytochemistry 1981, 20, 178-179.

4. Chen, K. S.; Wu, C. C.; Chang, F. R.; Chia, Y. C.; Chiang, M. Y.; Wang, W. Y.; Wu, Y. C. Bioactive coumarins from the leaves of Murraya Omphalocarpa. Planta Med. 2003, 69, 654-657.

5. Wickramaratne, D. B. M.; Kumar, V. Acid rearrangements of the murrangatins. Tetrahedron Lett. 1988, 47, 6153-6156.

6. Ito, C.; Furukawa, H. The chemical composition of Murraya paniculata. The structure of five new coumarins and one new alkaloid and the stereochemistry of murrangatin and related coumarins. $J$. Chem. Soc. Perkin Trans. 1 1990, 2047-2055.

7. Kinoshita, T.; Wu, J. B.; Ho, F. C. Prenylcoumarins from Murraya paniculata var. omphalocarpa (Rutaceae): the absolute configuration of sibiricin, mexoticin, and omphamurin. Chem. Pharm. Bull. 1996, 44, 1208-1211.

8. TEXSAN: Crystal Structure Analysis Package. Molecular Structure Corporation: The Woodlands, TX, 1992. 
9. Chen, K. S.; Ko, F. N.; Teng, C. M.; Wu Y. C. Antiplatelet and vasorelaxing actions of some benzylisoquinoline and phenanthrene alkaloids. J. Nat. Prod. 1996, 59, 531-534.

10. Chen, K. S.; Ko, F. N.; Teng, C. M.; Wu Y. C. Antiplatelet and vasorelaxing actions of some aporphinoids. Planta Med. 1996, 62, 133-136.

Sample Availability: Available from the authors.

(C) 2008 by MDPI (http://www.mdpi.org). Reproduction is permitted for noncommercial purposes. 